\title{
The analysis of glass ceiling phenomenon in the promotion of women's abilities in organizations
}

\author{
Mahboubeh Soleymanpour Omran $^{1}$, Homa Alizadeh ${ }^{2 *}$, Behrang Esmaeeli ${ }^{3}$ \\ ${ }^{1,2,3}$ Department of Educational Management, Bojnourd Branch, Islamic Azad University, Bojnourd, Iran
}

\begin{abstract}
Keywords:

Women constitute almost half of the workforce of a society and there has been considerable increase in women employment rate in recent years. However, their promotion to management

Glass Ceiling, Invisible Barriers, Glass Wall, positions has not been very tangible. Gender inequalities in the workplace especially in the Women domain of management have resulted in the lack of efficient use of potential capacities of women. Even though the previous research demonstrates that women are not less ambitious than men, wrong beliefs which attribute management to men make a kind of invisible barrier,

Correspondence: homaalizadeh77@gmail.com known as glass ceiling, which prevents women's promotion to top organizational positions. The purpose of this study was to investigate the reasons for the lack of promotion of women to top management levels in the society. It was conducted with a descriptive analytic method through the review of the related literature and emphasis on the concept of glass ceiling to present practical solutions to solve the problem.
\end{abstract}

(C)AIMI Journals

\section{Introduction}

The general conditions of organizations still show the effect of glass ceiling and staying of women in lower organizational positions. Various studies by different researchers (e.g., Abraham, 2013; Baxter \& Wright, 2000; Parcheta, Kaifi, \& Khanfar, 2013; Purcell, 2013) demonstrate that the presence of women and men in management positions is still unequal in many countries. Women constitute almost half of the population of every society and they are considered as the creators and trainers of next generations. They are potentially significant human resources in scientific, social, and cultural development of the country and, in 
consequence, special attention is required to the way of their occupational promotion. However, they mainly take low income jobs with unfavorable social status and other jobs which need proficiency and education are given to women on condition that on equal terms men are not willing to occupy those positions. At the present time, statistics show that the important role of women in the development of societies has always been neglected and the human society has suffered irreparable damage because of this issue. The present unfavorable situation created by gender inequalities has caused many countries to take various measures to eliminate discriminations and inequalities. Some of these countries have achieved notable success in the elimination of inequalities so that more than 40 per cent of decision-making positions are occupied by women in northern European countries such as Norway, Denmark, Finland, and in the US, the proportion of women's occupation has had a progress of 250 per cent compared to the 1970s. However, many of the developing countries, such as Iran, have not been successful in this issue during the 1990s. The latest statistics presented by Statistical Center of Iran show that there is a huge difference between the rate of economic participation of women and men so that this rate is 72.9 per cent for men and 18.5 per cent for women. The condition is even worse in the domain of management and decision-making in a way that only about 5.2 per cent of the managers of the country are women, and moving up the management levels this rate decreases to 1.4 per cent for the position of director-general and deputy director (Babaei, Khalili Eraghi, \& Yaghinlou, 2002). It is argued that the general atmosphere of organizations and male and even female managers and staff's distrust of women's abilities have created the current situation. This general pessimism toward women is dominant in the society while the number of academically educated women in Iran is increasing.

\section{Glass Ceiling}

The phenomenon of lack of promotion of women to upper levels of authority hierarchies is called glass ceiling. This term was first introduced in 1986 in Wall Street Journal and Morrison, White, and Van Velsor are the first researchers who used this term in 1987. This phenomenon was also studied in 1990 to show the scarcity of minorities and women in management of public and private organizations. In addition, it is sometimes used to represent deep wage gap in upper levels of income distribution so that according to Arfken, Bellar, and Helms (2004), female staff are paid lower in high-income groups compared to their male counterparts. Therefore, glass ceiling hinders minorities and women from 
achieving top levels of hierarchies. Davies-Netzley (1998) asserted that the glass ceiling metaphor is used to explain hidden obstacles, i.e., glass through which women can observe the best positions but cannot achieve them , i.e., ceiling. Therefore, they advance very close to high-ranking positions but rarely achieve them. This frustrating situation makes women conceive that there is a glass ceiling; that is, a kind of racial barrier, on the way of their achievement to the top management positions in organizations.

In order to study the effects of glass ceiling, many studies have tried to assess its different impacts on various hierarchical positions in organizations. Cotter, Hermsen, Ovadia, and Vanneman (2001) stated that "gender (or other) disadvantages are stronger at the top of the hierarchy than at lower levels and that these disadvantages become worse later in a person's career" (p. 655). They investigated gender and race inequalities at the $25^{\text {th }}, 50^{\text {th }}$, and $75^{\text {th }}$ percentiles of white male earnings. Besides, they gathered evidence of a glass ceiling for women, but racial inequalities and disproportion among men did not pursue a similar structure. Therefore, they concluded that glass ceilings was a distinctively gender phenomenon. On the other hand, Baxter and Wright (2000) stated that the glass ceiling hypothesis said that "not only it is more difficult for women than for men to be promoted up levels of authority hierarchies within workplaces but also that the obstacles women face relative to men become greater as they move up the hierarchy" (p. 275). However their findings from three countries of the United States, Sweden, and Australia were different from this definition. They discovered that the barriers women faced in possessing authority were considerable at the lower levels of the managerial hierarchy, not the upper levels in the United States. They also determined that there did emerge to be available glass ceiling effects in Sweden and Australia but situated more around the middle of managerial hierarchies than at the top. Therefore, women seemed to be mainly disadvantaged relative to men in changing from lower- to middle-management levels in these countries. In addition, Smith (2012) found in another study that, in contrast to the glass ceiling hypothesis, the white male has advantage over women. In addition, minorities in their salaries and retirement benefits did not develop with movement up the authority hierarchy net of controls. Instead, moderate inequality stayed constant at higher and lower levels of authority. 


\section{Sustainable Development and Equality}

Glass ceiling is a kind of inequality. Some criteria have been presented for recognition of inequalities caused by glass ceiling (Zahedi, 2003). In fact, studies show that women, exactly the same as men, start development and growth after their entrance to organizations and develop to different positions of organizations; but as they approach top positions, the pace of their progress and promotion decreases so that some invisible factors which are called glass ceiling hinder their progress. Obviously, this term shows a condition in organizations which there is no clear reason for women's inability to achieve higher positions, but in reality their achievement is not possible. Looking at top hierarchical positions of organizations, competent and qualified women see the status through this glass ceiling that they are competent enough to achieve, but because of invisible barriers they are not able to break through.

Survival in a developed condition is an important objective that all countries try to accomplish. The principles of sustainable development are defined according to the improvement of quality of life and empowerment of people. The realization of social justice is another basic requirement for the sustenance of development. In addition, one of the effective factors in development is the existence of equal opportunities for the empowerment of both women and men. Human development results in the existence of an environment where people are made able to believe their abilities comprehensively. Therefore, it can be said that human development depends on the extension of choices and the empowerment of people is one of the important requirements of extension of choices.

\section{Reasons for the Creation of Glass Ceiling}

In the long history of organizations, women were usually put in charge of low-ranking positions with repetitive tasks. Mostly, they performed their duties in staff positions or as assistant line managers and rarely they held the responsibilities of line managers (Yazdani, Roshanzade, \& Seyed-Javadin, 2007). A number of reasons have been presented for this backwardness of women in workplaces. Stereotypes, interpersonal channels of communication, valuation of women's work, work-family conflict, and management style are some of the factors which are mentioned as effective in the creation of barriers to the development of woman human resources in organizations.

The first important obstacle to women's promotion is gender stereotypes. Stereotype is a kind of thinking that considers all women the same and draws no distinction between them. 
Block and Crawford (2013) stated that "people exhibit gender stereotyping when they assign traits, behaviors, and roles to individual men and women on the basis of gender” (p. 9). Therefore, because of the prevalence of gender stereotypes, people generally believe that women and men are not alike (at least to some extent) in many aspects such as personality characteristics and gender features. As a consequence, gender stereotypes and the assumptions suggested by them receive priority over other classifications and characteristics. Some of these negative stereotype assumptions which draw a distinction between men and women are the beliefs that women are more willing to give precedence to family duties over business concerns; they are required to take care of their children; therefore, they lose the time and enthusiasm for their work; they work to earn extra income, thus they do not have enough enthusiasm for success in business; women take negative feedback personal instead of taking it professional; and finally, women are not suitable for top management positions because they are too sentimental and without aggression. Although these assumptions are probably true to a great extent for working women, they cannot describe women who are determined to pursue management as their professional career.

The second barrier for the progress of woman human resources is interpersonal channels of communication. Women, compared to men, have less interaction with powerful people of organizations and they are away from the center of power channels. Since the access to power channels has a direct relationship with promotion in organization, lack of opportunity to access these channels causes glass ceiling for women. In other words, women are mainly asocial and are deprived of informal interpersonal channels of communication. Elliott and Smith (2004) studied differential access to workplace power among women and minorities relative to white men. Their outcomes revealed that while women and minorities faced lower odds than white men of achieving higher levels of workplace power, the reasons for this drawback differed among seperate groups and therefore, probably demanded various solutions. In addition, Baerts, Deschacht, and Guerry (2011) investigated the role of the partner in promotions to top positions in Belgium. They concluded that women advantaged from their partner's sources and assets and they also wanted the opportunity and more particularly the time to do so.

The next effective factor in the creation of obstacles to the growth of women is valuation of women's work. Organizations expect all managers, either woman or men, to have the best performance, but the women's performance has particular importance. Working more than what is expected from men is a strategy used by successful female managers, and most of 
these women have considered it as an effective or partly important strategy. They were always required to prove their abilities, and in order to achieve this, they were always trying to overcome various negative assumptions in workplace which were usually made by men. Since men have less trust in women, female managers are forced to prove their abilities and capabilities. It seems that their contribution and partnership is not taken serious or valuable.

The fourth factor resulting in the lack of promotion of female human resources is the work-family conflict. Flexibility in work is one of the crucial factors which women need to make a balance between work and family responsibilities. Women who have the responsibility for the care of children do not usually have enough flexibility for working in the afternoon or out of working hours. Therefore, they are not able to meet many of the informal commitments, and even if they have the possibility to meet such commitments, they do not usually seem to be able to work overtime, thus they are excluded from the promotion list and are not able to hold a position of great authority. It is demonstrated that almost half of the women who leave their jobs and start an independent job are seeking for more flexibility. Suraj-Narayan (2005), in his research, studied the occupational stress which women were faced with and concluded that woman managers experienced several sources of stress; that is, work stressors, family stressors, personality and individual stressors as well as extraorganizational sources of stress.

Last but not least is management style which hinders the development of female human resources. Almost 96 per cent of female managers have mentioned application of a management style which is favorable to male managers as an effective factor for their lack of promotion. They are forced to accept masculine culture and environment and deal with a phenomenon called masculine management style. They have also acknowledged the fact that the existing management styles are filled with male characteristics and methods. These styles put women on dilemma so that if they apply female styles of management, they may be considered as unsuccessful managers; and if they accept male methods, they may be criticized that they are women and use male styles. In addition, other factors such as traditional employment networks, bias in employment and promotion of women, lack of endorsement of the right to equal opportunity, lack of enough education for occupying management positions, and considering female style of management as a direct threat to the men's opportunities for development are seen as some other obstacles which lead to glass ceiling (Taleghani, Pourezat, \& Faraji, 2009). 


\section{Strategies for Breaking through Glass Ceiling}

According to the discussion above, it can be stated that women are neither willing nor able to stay at this lower position forever and it is evident that many women have tried to eradicate this kind of gender discriminations. To deal with this issue, the International Labor Organization (ILO) have taken some measures such as educating women, making interpersonal channels of communication possible, adopting policies compatible with family interests, improving some of the recruitment rules, and increasing public awareness of the growing economic role and great contribution of women. However, the way should be also paved for taking advantage of woman human resources in management and decision-making levels through making it possible for women to recognize their own abilities.

It is also discussed that achieving the purposes of organizations and, in consequence, the development and growth of societies in different fields require a better and more active presence of professional women and men in operational processes. Women should know that despite efforts, still there are a lot of gender segregation and discrimination in public domains and achieving equality requires the presence and aid of many professional women and of course men (Adebowale, 1994).

In order to solve the glass ceiling problem, organizations and managers should take actions. At first, it is very necessary and important for organizations to change people's attitude and behavior, and to achieve this purpose, they should implement some policies and programs in different parts of the organizations. The most important kind of programs is the ones which change based on the time. These programs consist of implementing flexible working schedules, creating partnership jobs, and making the possibility of part-time jobs or shorter working days. Such a kind of programs allows woman managers and staff to solve the work-family conflict (Mirghafouri, 2006).

The second group whose special attention is required to break the glass ceiling is the group of managers. Women need skill, encouragement, self-confidence, and decisiveness to adapt themselves to the dominant masculine environment. The first skill required for the success of women is spending time to find appropriate career path. Women's career objectives are sometimes scattered and non-focused; therefore, they should try to find the most suitable career path compatible with their occupational and family conditions. The second skill which women need is the recognition of the fact that there is competition in organizations and women need to acquire suitable proficiency and proper conduct for competition. The next skill is creating the characteristics of self-confidence in women and 
causing them to trust their own abilities. Fourth, women should fight against time limitations. They need to be able to fulfill their duties on time. Another factor is learning political skills. Acquiring and implementing political skills is needed for playing the role of a successful manager by women. Fighting legal and regulation discrimination, providing job security, creating self-confidence to achieve complicated and sensitive jobs, constant education, fostering creative talents in women are other crucial strategies for improving the conditions of working women.

\section{Conclusion}

Women comprise half of the population of the society and as trainers of the next generation they have dramatic effect on comprehensive and sustainable development of the society. Therefore, breaking the glass wall which hinders women's progress through hierarchical positions is absolutely necessary for achieving sustainable human development. The main barriers to the development of women to top management positions are cognition barriers, valuation barriers, and legal barriers, and these happen in the condition that there is no logical reason for this backwardness of women (Mullins, 2009). Accomplishing different organizations' objectives and, in consequence, achieving sustainable development and social and economic development depend on taking full advantage of capacities and capabilities of valuable human resources of every country regardless of racial and gender discriminations (Hersey, Blanchard, \& Johnson, 2008). As a result, nowadays, women have effective presence in many social situations and where they do not have active presence, their absence is not because of their inabilities; it is because they were deliberately expelled from their suitable positions. Women have played such an effective role in every position that their performance was completely different from general assumptions of women as inactive wives and mothers. Unfortunately, despite the increasing positive presence of women in society, their status in society is still considered based on the duties attributed to them by the masculine society. Since inequalities between men and women is apparent in different parts of society, and considering the fact that progress and development of every society depends on making use of available expertise, it is extremely important to formulate scientific plans and appropriate programs to facilitate the conditions for presence and survival of women in society, and it is very crucial for reformers of society to take more positive stance toward women as half of the population of every society. 


\section{References}

Abraham, M. (2013). Does having women in positions of power reduce gender inequality in organizations? A direct test (Doctoral unpublished dissertation). MIT Sloan School of Management.

Adebowale, A. (1994). The glass ceiling: Women and mentoring in management and business. Employee Counselling Today, 6(1), 21-30.

Arfken, D. E., Bellar, S. L., \& Helms, M. M. (2004). The ultimate glass ceiling revisited: The presence of women on corporate boards. Journal of Bussiness Ethics, 50(2), 177-186.

Babaei, A. A., Khalili Eraghi, M., \& Yaghinlou, M. (2002). Women management: In a difficult transition. Tadbir, 126, 8085.

Baerts, A., Deschacht, N., \& Guerry M. A. (2011).The role of the partner in promotions to top positions in Belgium. European Sociological Review, 27(5), 654-668.

Baxter, J., \& Wright, E. O. (2000). The glass ceiling hypothesis: A comparative study of the United States, Sweden, and Australia. Gender \& Society, 14(2), 275-294.

Block, R. A., \& Crawford, K. C. (2013). Gender stereotypes of leadership behaviors: Social metacognitive evidence. Psychology \& Social Behavior Research, 1(1), 9-17.

Cotter, D. A., Hermsen, J. M., Ovadia, S., \& Vanneman, R. (2001). The glass ceiling effect. Social Forces, 80(2), 655-681.

Davies-Netzley, S. A. (1998). Women above the glass ceiling: Perceptions on corporate mobility and strategies for success. Gender \& Society, 12(3), 339-355.

Elliott, J. R., \& Smith, R. A. (2004). Race, gender, and workplace power. American Sociological Review, 69(3), 365-386.

Hersey, P., Blanchard, K. H., \& Johnson, D. E. (2008). Management of organizational behavior: Leading human resources (9th ed.). Englewood Cliffs, New Jersey: Prentice-Hall.

Mirghafouri, S. H. A. (2006). Identifying and ranking the effective factors contributing to the failure to appoint women to managerial positions in government agencies in Yazd province. Journal of Women's Studies, 1, 122-101.

Morrison, A. M., White, R. P., \& Van Velsor, E. (1987). Breaking the glass ceiling: Can women reach the top of America's largest corporations? Reading, MA: Addison-Wesley.

Mullins, L. J. (2009). Management and organizational behavior. London: Prentice Hall.

Parcheta, N., Kaifi, B. A., \& Khanfar, N. M. (2013). Gender inequality in the workforce: A human resource management quandary. Journal of Business Studies Quarterly, 4(3), 240-248.

Purcell, D. (2013). Baseball, beer, and bulgari: Examining cultural capital and gender inequality in a retail fashion corporation. Journal of Contemporary Ethnography, 42(3), 291-319.

Smith, R. A. (2012). Money, benefits, and power: A test of the glass ceiling and glass escalator hypotheses. ANNALS of the American Academy of Political \& Social Science January, 639(1), 149-172.

Suraj-Narayan, G. (2005). Women in management and occupational stress. Agenda: Empowering Women for Gender Equity, 65, 83-94.

Taleghani, G. R., Pourezat, A. A., \& Faraji, B. (2009). The effects of glass ceiling on the decrease of women's abilities in Electricity promotion organization of Iran. Public Management Journal, 1(2), 89-102.

Yazdani, H. R., Roshanzade, M., \& Seyed-Javadin, S. R. (2007). Presentation and explanation of a model for the analysis of causal relationship between women's self-concept, perception of glass ceiling, and glass ceiling. Scientific Research Journal of Women, 2(1), 1-40.

Zahedi, S. (2003). The promotion of women’s contribution in management positions in Iran. Management Knowledge, 62, 17-49. 